\title{
On Translation of Social Terms in Hong Lou Meng
}

\author{
Liqun Tsao \\ School of Languages and Culture, Shanghai University of Political Science and Law, Shanghai 201701, China \\ Email: caoliqun2010@126.com
}

\begin{abstract}
Translation is a bridge that leads different language speakers to understand each other. Translation of literature works, particularly those with large numbers of cultural elements, is the concern of translatology and many researchers. The Chinese classic novel Hong Lou Meng is right the case. This paper compares some cases in the address term translation in two different versions of translation, namely Yang Xianyi's and David Hawks', and tries to analyze them in combination with Lawrence Venuti's theory of domestication and foreignization.
\end{abstract}

Keywords: Hong Lou Meng, address terms, translation, culture

\section{Introduction}

Hong Lou Meng, the greatest masterpiece in China's history, has been the pinnacle of literature since its publication in the middle of the 18th century. With its incomparable writing style and unrivalled literary achievement, the novel stands side by side with War and Peace, and Hamlet.

The novel describes a saga of a big family, from its prosperity on the way to its fall, full of worldly elements of love, marriage, conspiracy, passion and death. It provides for readers with a magnificent picture of Chinese culture, with exquisite details of food, drink, gardening, architecture, poetry, opera, clothing, jewelry, herbal medicine, religion, manners of the time, etc. In fact, what Chinese readers can enjoy from the novel is more than the story itself: we feast our eyes on the fine and elegant cultural details that no longer exist in our time.

\section{Lawrence Venuti's theory of foreignization and domestication}

German philosopher Schleiermacher said in a speech in 1813 that in the process of translation, "Either the translator leaves the author in peace, as much as possible, and moves readers towards him; or he leaves the readers in peace, as much as possible, and moves the author towards them." (Venuti 1995: 19-20) He summarized that in translation, alienating and naturalizing were two frequently used strategies. Based on his theory, Italian American translation theorist Lawrence Venuti put forward his theory of foreignization and domestication in his book The Translator's Invisibility: A History of Translation in 1995.

In Anglo-American translation history, fluency was a dominant school that originated in Britain in the 17th century. According to Venuti, fluent translation is a form of violent translation that breaks the meaning of the original work into fragments. It lays much emphasis on language fluency and pays little attention to many other factors concealed in the language. In fact, there are plenty of extralinguistic elements in translation: political, economic, cultural, historical, and ideological, etc. When the source language is inferior to the target language, translators tend to yield to the superior culture and keep pace with the target language's values and ideology. In this sense Venuti puts forward resistant translation, later developed into his theory of foreignizing translation.

Resistance to fluency, or rather, resistance to cultural intrusion, is the key point in Venuti's theory of translation. He believes that the Anglo-American culture has foisted its aesthetics, values and ethics onto foreign texts and cultures, and thus he succeeds in elevating translation studies from the level of literature and linguistics to that of culture and politics. By means of resistance, translators should reject cultural narcissism and colonialism of the target language, and respect the culture and values of the source language.

In his The Translator's Invisibility: A History of Translation, Venuti is a firm believer and supporter of foreignizing translation and deconstruction. He deems that a translator is invisible to his readers because he has domesticated the original text to such an extent that readers do not feel that they are reading the translation of some foreign works. However, since cultural diversity is an indisputable fact, domesticating translation intentionally or unintentionally obliterate the cultural heterogeneity of the original text.

As a remedy, Venuti advocates foreignization, a strategy to highlight the visibility of a translator. He thinks that 
cultural differences are the most valuable part of a foreign text which a translator must strive to preserve and recreate in the translation. It is a translator's duty and obligation to bring his readers close to an exotic culture and enable them to understand and appreciate the diversities in values, aesthetics and ideology. It is, actually, completely unnecessary to lead the readers to a world of homogeneous culture they are brought up in by rewriting even distorting the foreign work.

\section{Different address terms in the East and the West}

It is held true in sociolinguistics that the more complex a society, the more complex its address terms, because address terms stand for protocol, hierarchy, status, power, etc. Generally speaking address terms can be categorized into kinship terms and social terms. Owing to the different historical background and cultural evolution, Chinese society attaches more importance to social hierarchy (the monarch above his subjects, the noble above the humble, the rich above the poor, superiors above inferiors, teachers above students, etc.), family status (fathers above sons, the older generations above the younger) and gender distinction (males above females). As a result, both kinship terms and social terms in China are far more complex than those in the West.

A case in point is the kinship term for grandson. Grandson in Chinese has to be divided into two different meanings: the son of a daughter and the son of a son. The son of a son, with the same family name, is the descendant within the family or clan, whereas the son of a daughter is an outsider because he has a different family name.

And the social terms in Chinese are so diverse and complex that even Chinese people ourselves have difficulty understanding and using them, honorific terms and modest terms in particular. In fact, social address forms stand for very complicated interpersonal relations and the mentality behind them.

\section{Comparison and contrast of social term translation in Hong Lou Meng}

Social terms, as an important part of sociolinguistics, reflect a country's social ethics and cultural orientation. The intact system of social address terms in Hong Lou Meng portrays for us a vivid picture of all walks of life, and with the help of the address forms, these people's ranks in officialdom and pecking orders in society are distinct and definite. Besides, Chinese people are known for their modesty, and for this reason in the address forms there are numerous honorific terms and modest terms, stating people's reverence for other people. These terms offer the readers a holographic blueprint of people living more than three hundred years ago.

Yang Xianyi and David Hawks began to translate Hong Lou Meng almost at the same time (in the 1960s and 1970s) without knowing that the other was working on the same book. It is very intriguing to compare the versions from the two translators.

\section{Example One}

In Chapter One, when Jia Yu-cun met Zhen Shi-yin, he said, “老先生倚门侣望，敢是街市上有甚新闻否? ”士隐 笑道: “非也。适因小女啼哭，引他出来作耍，正是无聊之甚，兄来得正妙 ......”

Yang: "What are you watching from your gate, sir? Is there any news in town?" "Nothing," was the reply. "My little girl was crying, so I brought her out to play. You couldn't have arrived at a better time..."

Hawks: "I could see you standing there, gazing, sir. Has anything been happening in the street?"

"no, no," said Shi-yin. "It's just happened that my little girl was crying, so I brought her out here to amuse her. Your coming is most opportune, dear boy..."

Jia Yu-cun, Zhen Shi-yin's temporary tenant, used the address “老 先生 ”, an honorific term to refer to an old gentleman, because he is junior in age and also in status. Both Yang and Hawks put “老先生” into “sir”, a word quite close in meaning to the original text.

What is interesting is how Zhen Shi-yin addresses Jia Yu-cun in his reply, “兄”. “兄 ”, older brother. Zhen Shi-yin is much older than Jia Yu-cun, so why does he call him “兄”? Foreign readers obviously cannot understand the context. In fact, “兄” or older brother is an honorific term to show one's respect and modesty. That is to say, whoever one is talking to, no matter what his age, "older brother" is a commonly used address among male speakers. However, neither Yang's "you" nor Hawks' "your" can convey the exact message in their conversation. In this case, domestication is the sole solution in translation.

Another interesting point in this conversation is Zhen Shi-yin’s “little girl”, “小女” in the text. Literally “小女” is "little girl", young daughter. Nevertheless, in Chinese, it can mean a daughter of older age, even when she reaches her adulthood. “小女” is a modest term used by Zhen Shi-yin to be polite and friendly. 


\section{Example Two}

In Chapter Three, Jia Yu-cun says to Lin Ru-hai, “不知令亲大人现居何职? 只怕晚生草率, 不敢骤然入都干渎。” 如海笑道,“若论舍亲，与尊兄犹系同谱，乃荣公之孙 ......”

Yang: "May I know your respected brother-in-law's position? I fear I am too uncouth to intrude on him." Ruhai smiled. "My humble kinsmen belong to your honorable clan. They're the grandsons of the Duke of Rongguo..."

Hawks: "I am afraid I do not know what your relation's position is at the capital. Might it not be a little embarrassing for a person in my situation to thrust himself upon him?"

Ru-hai laughed. "You need have no anxiety on that score. My brothers-in-law in the capital are your own kinsmen. They are grandsons of the former Duke of Rong-guo..."

In Chinese, “令” and “尊” are honorific terms, meaning “your". In the time of the novel it was ubiquitous for people to use these terms. In the conversation, obviously Lin Ru-hai's official rank is higher than Jia Yu-cun's. Nevertheless, this is the first time (and the last) Lin Ru-hai and Jia Yu-cun meet each other, so both of them use the honorific terms to show respect. Lin Ru-hai also uses the word “舍”, a modest term for himself to indicate politeness.

It is alright for Lin Ru-hai to use honorific forms for Jia Yu-cun and modest terms for himself. Social manners are required here to show noble class' superior family background and upbringing. It is believed in Chinese culture that the more education one acquires, the more refined in his manners.

Jia Yu-cun, on the other hand, has some ulterior motives in his speech. Once an official himself, he is eager to have some opportunity to go back to the political career. On learning that Lin Ru-hai is related by marriage to Family Jia, he realizes that his good luck is coming. When inquiring Lin Ru-hai's kinship relations with Jia, he spontaneously uses terms of modesty to flatter Lin Ru-hai.

Let us try to contrast the two versions of translation. Yang used "your respected bother-in-law" for “令亲”, while Hawks "your relation". Yang's version of “尊兄” is “your honorable clan", and Hawks' "your own kinsmen". Clearly Yang was trying to be faithful to the original work, and applied the translation strategy of foreignization to emphasize much on the source language, so that the artistic conceptions of the original language was reconstructed to a large degree. By contrast, Hawks' version is much simpler: he did not translate the honorific terms in the source language and used "your" for “令” "and “尊”, a strategy of domestication.

There are two modest terms in this conversation. One is “舍亲”, “舍” a modest term for “my”. Yang translated the word into "my humble kinsmen", and Hawks "my brothers-in-law". It is clear to us that Hawks employed the strategy of domestication to ensure that English readers can follow the speaker and immerse themselves into the novel without difficulty.

The other one is “晚生”. This is a modest term for younger generations to address themselves in front of the older ones, especially among intellectuals. Literally the word means someone who is born later. Let's see the translation above: Yang tried to preserve the original work's address forms and managed to translate the honorific terms like "令 " and “尊”, and modest terms like “舍”, but he failed to translate “晚生”, for the only reason that there is no equivalent word for “晚 生” in English. Both of the translators had to use "I" or "my" to replace the original word.

As a matter of fact, if western readers cannot understand the word “晚 生”, then it would be more difficult to understand the next example.

\section{Example Three}

In Chapter 42, when Dowager Jia is unwell, a doctor is sent for. Learning that the doctor's name is Wang, the dowager says, “当日太医院正堂有个王君效，好脉息。”王太医忙躬身低头含笑，因说：“那是晚晚生的家叔祖。”

Yang: "In the old days," Lady Dowager said, "the director of the Academy of Imperial Physicians, Wang Junxiao, was an excellent diagnostician."

Wang bowed and, his head lowered, rejoined with a smile, "He was my great-uncle."

Hawks: "When I was a young woman, the President of the Imperial College of Physicians was a Wang," said Grandmother Jia, "Wang Junxiao. Famous for his diagnoses."

The doctor bowed.

"He was my great-uncle," he said.

Another modest term, but this time “晚晚生”. Please compare it with “晚生” in Example Two. As is mentioned above, “晚生” means someone who is born later, and “晚晚生” means someone who is born even later. In other words, “晚 生” means the next generation, and “晚晚生” the generation after the next.

Reading the context, readers can easily understand why Doctor Wang calls himself “晚晚生”: His great uncle Wang 
Junxiao probably paid home visits to Family Jia, and he was of the similar generation or age to the old lady. “晚生 ” is not enough to indicate Doctor Wang's age and position, and “晚晚生” is more proper. It is a common practice for people of that time to distinguish among themselves with these modest terms to show respect and courtesy.

Doctor Wang works for the royal family, and often he pays home visits to noble families like Jia, therefore almost all his patients are aristocrats. In this sense he must be very proficient in using address forms. In addition, in Chinese culture since age is an important element to mark people's status and position, it is natural for him to call himself “晚晚生” in front of the lady whose age and status are equivalent to his great uncle.

Unfortunately, there is no equivalent for “晚生”, let alone “晚晚生”. In both of the two versions “晚晚生” is put into "my", a frustrating substitution or simplification with a complete loss of the original meaning.

J. C. Catford deems that there are two forms of untranslatability: linguistic and cultural. At the linguistic level words such as puns, homonyms, homophones, polysemies, etc. are untranslatable. Cultural untranslatability dates back to heterogeneous historical backgrounds between cultures. As a result, deficiency of cultural horizon contributes to lack of words and understanding, and thus limitation of cognition.

In the case of “晚晚生”, the Chinese culture puts much emphasis on age and generation so that respect for the elderly is a national virtue. This kind of respect is embodied not only in a family but in a civilized society. In Hong Lou Meng Dowager Jia belongs to the oldest generation, and she is the decision-maker in the family who enjoys a supreme status. Meanwhile Doctor Wang's prudent use of address form “晚晚生” is exactly where the quintessence of Chinese cultural values lies. It is just because with the use of social address terms, people's relations, status, class, power and age are clear at a glance that the translation of address terms is extremely conspicuous and intriguing.

\section{Example Four}

In Chapter 33, when Jia Zheng, Bao-yu's father, learns that an officer from the household of Prince Zhongshun comes to visit him without an appointment, he hurries to meet him. The officer says, without customary greetings, “下官此来, 并非擅造潭府; 皆因奉命而来, 有一件事相求。看王爷面上, 敢烦老先生做主。不但王爷知情, 且连下官辈亦感 激不尽。”

Yang: The chief steward did not beat about the bush.

"Excuse the presumption of this intrusion," he said. "I come at the order of the prince to request a favor. If you, my lord, will grant it, His Highness will remember your kindness and I shall be infinitely indebted to you."

Hawks: The chamberlain cut short the customary civilities by coming straight to the point.

"It would have been temerity on my part to have intruded on the leisure of an illustrious scholar in the privacy of his home, but in fact it is not for the purpose of paying a social call that I am here, but on orders from His Highness. His Highness has a small request to make of you. If you will be so good to oblige him, not only will His Highness be extremely grateful himself, but I and my colleagues will also be very much beholden to you."

According to the novel, the chief steward/chamberlain is here to find fault with Jia Zheng, or his son Bao-yu. In this part of the conversation the chief steward/chamberlain is arrogant and overbearing in his tone toward Jia Zheng by using a modest term for himself (“下官”) and an honorific term for Jia Zheng (“老先生”), which is really provocative and defiant.

“下 官”, an term for courtesy used by junior officials in front of senior ones, is untranslatable in both of the two versions. Yang directly used “I” for “下官” and Hawks “my”. Again no equivalent. And the honorific term “老先生” means an old gentleman. The chief steward/chamberlain's use of this word is so acerb in the conversation that it sounds very harsh and unpleasant in the context. Yang's "you, my lord" sounds quite proper here, while Hawks" "you" is a little bit out of place. In the whole novel, no one calls the other "you" unless he or she is higher in status or older in age.

Jia Zheng, father of the imperial consort, is a senior official in the government who deserves respect from other officials. Nevertheless, the chief steward / chamberlain from the household of Prince Zhongshun takes advantage of these formal terms to mean disrespect and even disgust. The scornful and sarcastic attitude concealed under the mask of modesty and civility is unbearable to such an extent that Jia Zheng flies into a rage and beats Bao-yu up after the chief steward leaves.

In fact, these address terms are used to indicate not only one's post, status, hierarchy and power, but also one's mental inclination and personal attitude. It is held true in sociolinguistics that the more polite words one uses, the more alienated he is. The chief steward uses humble words to show superficial respect, but in fact what he means is exactly the opposite, and he manages to serve his purpose. 


\section{Example Five}

In Chapter 18, Yuanchun, Jia Zheng and Lady Wang’s eldest daughter, the imperial consort, visits her parents on Lantern Festival. During the brief family reunion, Jia Zheng says to his daughter, “臣草芥寒门，鸠群鸦属之中，岂意得 征风鸾之瑞。今贵人上锡天恩，下昭祖德，此皆山川日月之精华，祖宗之远德，钟于一人，幸及政夫妇 ......贵 妃切勿以政夫妇残年为念 ......”

Yang: With tears too he replied, "Your subject, poor and obscure, little dreamed that our flock of common pigeons and crows would ever be blessed with a phoenix. Thanks to the Imperial favor and the virtue of our ancestors, your Noble Highness embodies the finest essences of nature and the accumulated merit of our forebears - such fortunes has attended my wife and myself...... Your Noble Highness must not grieve your precious heart in concern for your aging parents....."

Hawks: With tears in his eyes the good man delivered the following little speech to the daughter he could not see:

"Madam,

That a poor and undistinguished household such as ours should have produced, as it were, a phoenix amidst a flock of crows and pies to bask in the sunshine of the Imperial favour and shed its reflected beams on the departed representatives of our ancestral line must be attributable to the concentration in your single person of quintessences of all that is most admirable in celestial and terrestrial nature and the accumulated merit of many generations of our forebears, and is an honour and a blessing in which my wife and I are proud to be participators...... and that Your Grace should feel no anxiety concerning the welfare of my wife and myself during our now declining years......"

The occasion is extremely representative in the novel in terms of address terms. In Confucian philosophy, the relations between a monarch and his ministers takes priority over all the others. Those in a family and between husband and wife have to yield. In other words, despite the fact that Jia Zheng and Lady Wang are Yuanchun's parents, they must kowtow at her feet. Compared with Bao-yu, Yuan-chun's full brother, who calls Jia Zheng “老爷”, and is translated into “the master” by Yang and "Sir Zheng" by Hawks (Chapter 33), Yuan-chun is supposed to address her father with the similar term, provided that she is not an imperial consort Thereby the kinship terms between the parents and their daughter are converted into social terms.

Jia Zheng addresses himself “臣”, meaning a subject. However, there is no such use of address terms in English. Yang's "your subject" is quite equivalent to “臣”, a case of literal translation agreeing with the original use of the word and its meaning. Hawks' translation of “madam" is adroit. He tactfully avoids translating “臣” in his work for the probable reason that there is no such address term in English. However, with the context both of the translators succeed in trying to convey the original message to the English readers.

In fact, in the Chinese language, there is an integrated system of address forms among royal families, as well as between royal families and their subjects. No one dares to call himself or herself "I" in front of a royal family. In contrast, there are only a few terms in English such as "Your Majesty", "Her Highness", "Your Grace", "My Lord", etc. As a consequence the translation of these terms in the novel is doomed to encounter word absence.

Let's look at Jia Zheng’s address for Yuan-chun “贵人”, “贵妃”, with the similar meaning of an imperial consort, right next to the queen. Yang put both of the words into "Your Noble Highness", and Hawks translated “贵人” into “your”, “贵妃” “Your Grace”. “Your Noble Highness” and "Your Grace” are appropriate as honorific terms, but not "your”. As a matter of fact, in Hong Lou Meng, people are not allowed to address other people of higher rank, status or of older age "you", since it is direct and commanding. In this case Hawks' domestication of "your" is rather awkward in the context.

For the same reason, when Jia Zheng mentions himself and his wife in front of Yuan-chun, he is not allowed to use "we" or “us”. Instead, he uses “政夫妇”, with “政” Zheng, himself, and “夫妇”, couple, husband and wife. In both versions “政 夫妇” is put into “my wife and myself”, a compromise in translation, because “政夫妇” in the original work is a modest term, but the connotation cannot find an equivalent in English.

It would be easy for Chinese readers to understand these special terms, but difficult for foreign readers, because these terms are so commonly used even in today's Chinese language while they do not exist in English. In these two versions of translation, foreignization and domestication seem to be conflicting: the former facilitates English readers' understanding of the context, but with certain information lost. The latter retains the original work's style and the author's intention to the largest extent. However, foreigners would find it difficult to follow.

Personally I am inclined to the strategy of foreignization for the simple reason that it manages to preserve most (if not all) of the qualities of the original writing style and artistic conceptions. If readers like the novel, they will go on with their reading, and slowly they can perceive the delicacy and elegance of these small details. Domestication, on the other hand, enables foreign readers to follow more quickly, while the artistic style and cultural information or connotation will be lost, thus they forfeit the lingering aroma of such an exquisite novel. 


\section{Conclusion}

It has been widely acknowledged that translation of a novel is more a process of cultural transmission than that of mere textual reproduction. The process is more about values, traditions, philosophy, aesthetics, ethics, ideology, and even politics. In other words, in order to enable foreign readers to appreciate a novel, a translator must respect and retain, as much as possible, the cultural details in the original text, no matter how seemingly trivial they are.

Venuti lays great emphasis on foreignizing translation, holding that domestication sacrifices source language culture and yields to target language culture. A translator is supposed to be "invisible" because he is there to lead his readers along the path of adaptation and not to force the readers to follow his way.

The process of translation is also an opportunity to understand and recognize more profoundly the nature of a language and the differences between languages and cultures. The purpose of translation, thus, lies not in seeking common ground but in reserving differences. A translator must be conscious of the importance of preserving the original text's cultural characters and try to resurrect for the readers the cultural ambience in his translation.

It is reckoned that translators must be convinced of readers' capability to understand the exotic cultures, because their intellect and imagination can help them appreciate the alien parts of other cultures. By being exposed more to new horizons, there will be no soil for the seeds of cultural misconceptions and preconceptions. The information and messages from a novel help form an intact system of multi-cultural value orientation, thus avoiding nationalism and ethnocentrism.

\section{References}

[1] Cao Xueqin, Gao E. A Dream of Red Mansions. Beijing: People's Literature Publishing House; 1987.

[2] Gao Yulan. A Study of Cultural Translation from the Perspective of Deconstruction: Taking the English Version of A Dream of Red Mansions as an Example. Available from: https://kns.cnki.net $/ \mathrm{kcms} / \mathrm{detail} / \mathrm{detail}$.aspx?dbcode=CDFD\&dbname $=$ CDFD0911\&filename $=1011018248 . n h \& v=c \% 25 m m d 2 B n G k R N 1 H w L T Z h G 5 H Z S O r 8 P k u 1$ o0GTlwegJr967cllHKE7D2ZtWvbj79aDUvtzWq

[3] Zhu Yubin. Linguistic Untranslatability and Cultural Untranslatability: A Comment on Catford's Translatability Theory. Journal of Hefei University of Technology (Social Science Edition). 2004; 18(3): 151-153.

[4] Venuti Lawrence. The Translator's Invisibility: A History of Translation. London and New York: Routledge; 1995.

[5] Cao Xueqin. A Dream of Red Mansions. Translated by Yang Xianyi and Gladys Yang. Beijing: Foreign Language Press; 2010.

[6] Cao Xueqin. The Story of the Stone. Translated by Hawkes and Minford. London: Penguin Classics; 1973. 